\title{
Reduction of airborne allergenic urinary proteins from laboratory rats
}

\author{
Susan Gordon, Rosemary D Tee, D Lowson, J Wallace, A J Newman Taylor
}

\begin{abstract}
Allergy and asthma caused by proteins of laboratory animals, particularly rats and mice, are the most important occupational health hazards for the scientists and technicians who work with such animals. The influence of different cage litters, cage design, and stock density on measured rat urinary aeroallergen (RUA) concentrations has been examined in a room housing male rats, to determine practical means to reduce allergen concentration in animal laboratories. Eight hour static air samples were taken at $21 /$ min and the RUA concentrations measured by radioallergosorbent test (RAST) inhibition. High RUA concentrations occurred when the animals were housed on wood based, contact litter (geometric mean (GM) sawdust $7 \cdot 79$ $\mu \mathrm{g} / \mathrm{m}^{3}$; woodchip $\left.6.16 \mu \mathrm{g} / \mathrm{m}^{3}\right)$. The use of noncontact absorbent pads was associated with a significant decrease in RUA concentrations (GM $2.47 \mu \mathrm{g} / \mathrm{m}^{3} ; \quad$ p $<0.0001$ ). Rat urinary aeroallergen concentrations fell more than fourfold when the animals were housed on woodbased, contact litter in filter top cages rather than conventional open top cages (GM filter top $0.33 \mu \mathrm{g} / \mathrm{m}^{3}$; open top $1.43 \mu \mathrm{g} / \mathrm{m}^{3}$; $p<0.0001$ ). The number of rats (stock density) strongly influenced the RUA concentration and a linear relation was found between the $\log _{\mathrm{e}}$ allergen concentration and stock density under these study conditions. The measurement of airborne particle size on cleaning out days showed that all litter types generated similar sized particles: more than $80 \%$ of the RUA was carried on particles larger than $8 \mu \mathrm{m}$ in diameter for all litter types. The findings
\end{abstract}

Department of Occupational and Environmental Medicine, Emmanuel Kaye Building, National Heart and Lung Institute, Manresa Road, London, SW3 6LR

S Gordon, R D Tee, D Lowson, A J Newman Taylor

Haddow Laboratories (Block X), Institute of Cancer Research, 15 Cotswold Road, Belmont, Sutton, Surrey SM2 5NG $\mathrm{J}$ Wallace suggest that the exposure of animal husbandry personnel to RUA may be substantially reduced by the avoidance of contact litter, the use of filter top cages (where suitable), and by keeping stock density to a minimum.

In 1986 in the United Kingdom, 11000 animal licence holders undertook 830000 experiments involving rats. ${ }^{1}$ Cross sectional epidemiological surveys have shown that about one third of people exposed to laboratory animals experience allergic symptoms ${ }^{2-8}$ and up to $10 \%$ have asthma, ${ }^{478}$ many of whom may ultimately have to seek alternative employment. Allergy to laboratory animals is an important health hazard for both research scientists and animal husbandry personnel. The risk of its occurrence is probably related to airborne allergen concentration and reducing exposure by the use of respiratory protection has been shown to decrease the incidence of disease. ${ }^{9}$ Laboratory animal allergy and asthma are potentially preventable if exposure to animal aeroallergens can be reduced sufficiently.

In 1988 regulations were introduced that require employers to identify, assess, and minimise the risk of harmful substances hazardous to the health of their employees (The Control of Substances Hazardous to Health Regulations (COSHH)). A method suitable for the measurement of aeroallergen concentration was first described by Agarwal et al in $1981 .{ }^{10}$ Several groups have subsequently reported similar approaches to estimate exposure to laboratory animal allergens, ${ }^{11-16}$ but there have been no large controlled studies of the effectiveness of simple methods to reduce airborne animal allergen concentrations.

Urine is the major source of rat allergens. ${ }^{17} \mathrm{We}$ have measured rat urine aeroallergen concentrations under different husbandry conditions in a room assigned specifically to this study to ascertain what practical steps can be taken to reduce aeroallergen concentrations.

Materials and methods

ANIMAL HUSBANDRY

Sixty male HSD/OLA Wistar rats (Harlan Olac Ltd, Bicester, Oxon) around three months old were housed according to Home Office code of practice ${ }^{18}$ in 
a room (size $3.7 \mathrm{~m} \times 2.3 \mathrm{~m} \times 2.3 \mathrm{~m}$ ) assigned solely to this study (maximum stock density 3.1 male rats $/ \mathrm{m}^{3}$ ) and separate from other animal rooms. Access to the room was restricted to the animal technician responsible for the daily care of the animals and the research scientist performing the study. The room was ventilated at a rate of 18 air changes per hour and kept at positive pressure to the corridor. The temperature and relative humidity were controlled between $18^{\circ} \mathrm{C}$ to $20^{\circ} \mathrm{C}$ and $50 \%$ to $60 \%$.

Animals were checked daily and provided with expanded laboratory diet (Bantin and Kingman Ltd, Grimston, Hull) and water ad libitum. The soiled bedding was changed twice weekly (cleaning out). The animals in open top cages were put into clean cages and the soiled bedding transferred to a receptacle within the study room. The filter top cages were removed from the room before cleaning out. The floor was wet swept daily and washed after cleaning out.

Static (area) and personal air samples were collected as described later to evaluate the change in RUA concentrations when three animal husbandry procedures likely to influence allergen concentrations were altered.

\section{(1) Litter type}

Comparisons were made between the use of contact (woodchip and sawdust) and non-contact (absorbent pads) litter types.

Animals were housed in open top cages (Type RC 1 , North Kent Plastics, Erith, Kent) in racks, five rats a cage, at a height of $0.3-1.7 \mathrm{~m}$ above the floor. Absorbent pads (Beta-sorb multilayer tray liners $250 \mathrm{~mm} \times 650 \mathrm{~mm}$ divided in two; Beta Medical and Scientific (Datesand Ltd), Sale), woodchip (graded shavings; Datesand Ltd), or sawdust (woodflakes, grade 6; Datesand Ltd) litter were used sequentially for two weeks each. Both the wood based sawdust and woodchip litter were described as dust free by the manufacturer. The animals were directly in contact with the wood based litter but were separated from the absorbent pads by a grille floor (RC 1 with grid bottom). The room was left unoccupied by animals for two days between experiments to enable a baseline measurement to be taken.

\section{(2) Cage design}

Thirty rats were housed three per cage on woodchip bedding in solid bottom, open top, and filter top cages (Techniplast, Varese, Italy). The filters for the cages were made from $100 \%$ polyester and retained $87 \%$ of $1.5 \mu \mathrm{m}$ particles at a Frazier air permeability of 350 cubic feet per metre. The filter top cages were placed directly on the floor due to the unavailability of a suitable rack.

To evaluate the effect of cage design, these measurements were compared with those collected in the presence of 30 rats in the stock density experiment series.

\section{(3) Stock density}

To assess the influence of stock density on RUA concentrations, fifteen rats were removed from the room each week, reducing the stock density from $3 \cdot 1$ male rats $/ \mathrm{m}^{3}$ to no male rats $/ \mathrm{m}^{3}$ over five weeks. All the animals were housed on woodchip bedding in solid bottom, open top cages in racks.

\section{AIR SAMPLING}

Personal air samplers (AFC 123, Casella London Ltd, London) were used to collect static (area) and personal air samples. Samples were collected at $2 \mathrm{l} / \mathrm{min}$ with $25 \mathrm{~mm}$ diameter seven holed sampling heads (Casella London Ltd) on to polytetrafluoroethylene (PTFE) filters $(1.2 \mu \mathrm{m}$ pore size; Sartorius Instruments Ltd, GB-Belmont, Surrey).

\section{Static (area) samples}

Four sampling pumps were placed around the room at an average height of $1.8 \mathrm{~m}$. Figure 1 shows the position of the sampling pumps in relation to the

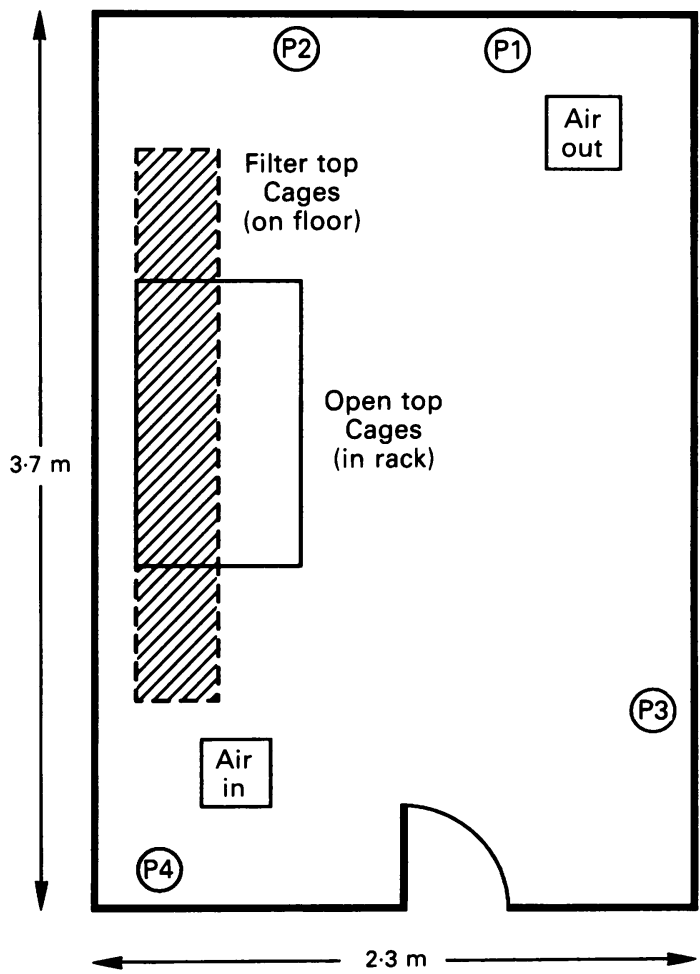

Figure 1 Plan of study room showing position of air samplers (pumps P1 to P4) in relation to animals and ventilation. The ventilation was at ceiling height. 
ventilation system. Eight hour samples were collected except immediately before the introduction of the rats after husbandry changes when four hourly baseline samples were taken.

\section{Personal samples}

The animal technician wore the personal sampler while cleaning out the rats. The sampler was switched off immediately after the task was completed, a total sampling time of about 20 minutes.

\section{Particle sizing}

To determine the particle size of the dust generated on cleaning out days, an eight stage Marple cascade impactor (Sierra Instruments, distributed by Schaeffer Instruments Ltd, Oxon) was used as a static sampler. Eight hour samples were collected at $2 \mathrm{l} / \mathrm{min}$ on to glycerol gelatin (Sigma Chemical Co, Dorset) coated Mylar membranes (Schaeffer Instruments Ltd) according to the manufacturer's recommendations. Samples were collected in the presence of 60 rats housed on both types of wood based, in contact litter and the absorbent pads. One measurement was taken per litter type.

\section{Elution of filters}

All filters were eluted in $2 \mathrm{ml} 0.1 \mathrm{M} \mathrm{NH}_{4} \mathrm{HCO}_{3}(\mathrm{pH}$ $7 \cdot 0-7.5)$ with $0.5 \% \mathrm{v} / \mathrm{v}$ Tween 20 for two hours ${ }^{19}$; PTFE filters in Sterilin RT-30 tubes $(7.4 \times 1.1 \mathrm{~cm})$ (distributed by A1 Laboratory Supplies, London) by vortexing at $2 \times 1$ hour intervals, and Mylar filters by rocking and rolling in sealed $6 \mathrm{ml}$ plastic Sterilin containers (12 × $50 \mathrm{~mm}$; A1 Laboratory Supplies). Filter eluates were freeze dried and reconstituted before assay.

\section{AEROALLERGEN ASSAY}

Preparation of reagents

Urine was collected daily from four month old male Wistar rats using a metabolic cage (Techniplast). The pooled urine was filtered (Whatman, Grade 1), concentrated, dialysed against distilled water, and lyophilised.

Paper discs $(6 \mathrm{~mm}$; Schleicher and Schuell, distributed by Anderman Company Ltd, KingstonUpon-Thames) were activated with cyanogen bromide (Sigma Chemical Company). Three mg lyophilised rat urine was coupled per $300 \mathrm{mg}$ of activated discs by the method of Ceska et al. ${ }^{20}$

\section{$R A S T$ inhibition assay}

The RUA concentration of the air samples was determined by RAST inhibition. Briefly, pooled sera from 15 patients allergic to rat urine (diluted 1:16 with $0.1 \mathrm{M}$ phosphate buffered saline (PBS) containing $0.3 \% \mathrm{w} / \mathrm{v}$ human serum albumin and $0.1 \% \mathrm{w} / \mathrm{v}$ sodium azide) $(50 \mu \mathrm{l})$ were incubated overnight in duplicate with an equal volume of air sample or rat urine standard $(0.0$ and $1.0 \mathrm{mg} / \mathrm{ml}$ to $10 \mathrm{ng} / \mathrm{ml}$ in $10-$ fold dilutions). A rat urine RAST was then performed on the inhibited samples and bound $\operatorname{IgE}$ detected using ${ }^{125}$ I labelled anti-IgE (Pharmacia, Uppsala, Sweden).

The standard curve percentage inhibition (p) data adhered to previously described criteria ${ }^{21}$ and was therefore logit transformed using $\log _{e}(p /[1-p])$. When plotted against log concentration, a straight line could be fitted and from it the rat urine concentration $([R U] \mathrm{mg} / \mathrm{ml}$ ) of the air samples interpolated. The RUA concentration was then calculated as:

$\operatorname{RUA}\left(\mu \mathrm{g} / \mathrm{m}^{3}\right)=\frac{[\mathrm{RU}] \times \text { reconstituted volume }(\mathrm{ml})}{\text { vol of air sampled }\left(\mathrm{m}^{3}\right)}$

The limit of detection for the assay was $50 \mathrm{ng} / \mathrm{ml}$.

\section{STATISTICAL ANALYSIS}

All statistical analyses were made on the log transformation $\left(\log _{e}\right)$ of the allergen measurements with the statistical package SAS.

A three factor analysis of variance (ANOVA) was used initially. This tested for differences between mean RUA concentrations due to litter type, pump position, and the influence of cleaning out and noncleaning out days. Tukey's studentised range test was used to provide more detailed information about the differences between the means. A two way analysis of variance was also used to test for differences in RUA concentrations due to cage design and pump position. Evidence was sought for interaction of effects in both of the analyses.

Analysis of covariance was used to describe the allergen concentrations by the number of rats in the animal house, pump position, and whether or not it was a cleaning out day.

\section{Results \\ LITTER TYPE}

Figure 2 shows the RUA concentrations measured in the presence of 60 rats housed on absorbent pads, woodchip, and sawdust bedding. The baseline values of $0.07,0.19$, and $0.78 \mu \mathrm{g} / \mathrm{m}^{3}$ (the GM of the concentrations recorded when the room was empty) were subtracted from the absorbent pad, woodchip, and sawdust litter results respectively.

The highest RUA concentrations measured were when animals were housed on wood based, in contact litter and the lowest with absorbent pads (GM woodchip $6.16 \mu \mathrm{g} / \mathrm{m}^{3}$; sawdust $7.79 \mu \mathrm{g} / \mathrm{m}^{3}$; absorbent pads $2.47 \mu \mathrm{g} / \mathrm{m}^{3}$ ). The difference between the contact and non-contact litter types was significant $(p<0.0001)$. The difference between the means of the sawdust and absorbent pads was $1.15 \mu \mathrm{g} / \mathrm{m}^{3}$, and between woodchip and absorbent pads $0.91 \mu \mathrm{g} / \mathrm{m}^{3}$. 


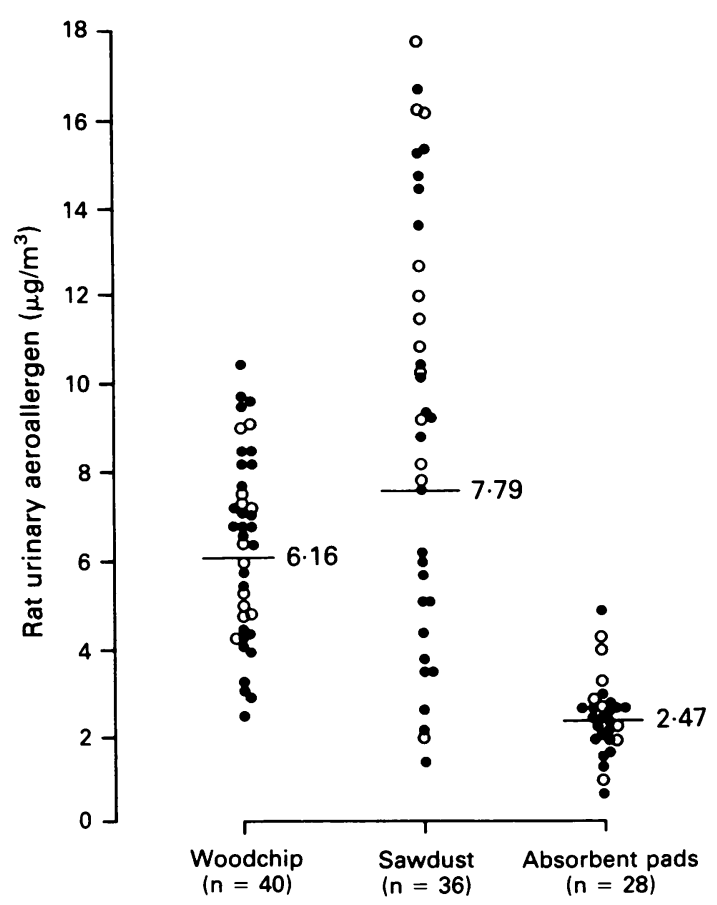

Figure 2 Comparison of litter type. Rat urinary aeroallergen concentrations measured when 60 rats were housed on woodchip and sawdust in contact litter, and absorbent pad, non-contact litter. The measurements made on cleaning out days are shown as open circles. The geometric mean (GM) is indicated.

\section{Effect of pump position}

Some differences were found between the RUA concentrations measured by the individual pumps $(p$ $<0.02$ ). Tukey's studentised range test showed differences between pumps 1 and 2 and 1 and 3 . The mean RUA concentrations measured (for all bedding types) for pumps $1,4,3$, and 2 were $6 \cdot 63,5 \cdot 33,4 \cdot 63$, and $4.57 \mu \mathrm{g} / \mathrm{m}^{3}$.

\section{Effect of cleaning out}

Differences were found in the RUA concentrations measured on cleaning out and non-cleaning out days ( $p<0.04$ ). The mean RUA concentrations (for all pumps and all bedding types) on cleaning out days was $6 \cdot 14 \mu \mathrm{g} / \mathrm{m}^{3}$ and on non-cleaning out days $4 \cdot 86 \mu \mathrm{g} / \mathrm{m}^{3}$.

No evidence was found for interaction of pump position, cleaning out, and litter type.

\section{Particle size}

Table 1 shows the distribution of allergen particles. Because of the large differences between the total amounts of allergen captured for each litter type, the allergen captured on each stage has been expressed as a percentage of the total.
Greater than $80 \%$ of the allergen generated on cleaning out days was carried on particles larger than $8 \mu \mathrm{m}$ diameter regardless of the litter used. Slight differences were found in the distribution of particles generated by the different litter; $63 \%$ of the allergen generated by the woodchip was carried on particles $>10 \mu \mathrm{m}$ compared with $55 \%$ for sawdust and $48 \%$ for absorbent pads. Also, there was some evidence that the absorbent pads produced more allergenic particles less than $1 \mu \mathrm{m}$ than the other wood based litters.

\section{CAGE DESIGN}

Figure 3 shows the concentrations measured in the presence of 30 rats housed on woodchip litter in open top and enclosed filter top cages. For the purpose of comparison, the measurements made on the cleaning out days for the open top cages have been omitted as the cleaning out occurred within the study room. Two data points from the filter top group were less than the baseline value of $0.16 \mu \mathrm{g} / \mathrm{m}^{3}$ and were therefore removed from further analyses.

A highly significant difference in aeroallergen concentration was found when filter top cages were used ( $p<0.0001$ ). The GM RUA decreased from $1.43 \mu \mathrm{g} / \mathrm{m}^{3}$ with open top cages to $0.33 \mu \mathrm{g} / \mathrm{m}^{3}$ with filter top cages.

\section{Effect of pump position}

No significant differences were found in the RUA concentrations recorded by individual pumps.

No interaction between cage design and pump was seen.

\section{STOCK DENSITY}

Reducing the number of rats in the room decreased the RUA concentrations measured (fig 4A). The GM aeroallergen concentrations recorded in the presence of $3 \cdot 1,2 \cdot 3,1 \cdot 5,0 \cdot 8$ male rats per $\mathrm{m}^{3}$ were $8 \cdot 09,3 \cdot 59$,

Table 1 Distribution of allergen particles for sawdust $(S)$, absorbent pads $(A P)$, and woodchip (W) litter during cleaning out. The allergen collected on each stage is expressed as a percentage of the total allergen

\begin{tabular}{|c|c|c|c|c|}
\hline & \multirow[b]{2}{*}{ Aerodynamic diameter ( $\mu m)$} & \multicolumn{3}{|c|}{$\begin{array}{l}\text { Allergen particle } \\
\text { distribution (\%) }\end{array}$} \\
\hline & & $s$ & $A P$ & $W$ \\
\hline \multicolumn{5}{|l|}{ Stage: } \\
\hline $\begin{array}{l}1 \\
2 \\
3 \\
4 \\
5 \\
6 \\
7 \\
8 \\
\text { back up }\end{array}$ & $\begin{array}{l}>19 \\
12-10 \\
10-8 \\
8 \cdot 0-4.5 \\
4.5-2.9 \\
2.9-1 \cdot 1 \\
1 \cdot 1-0.7 \\
0.7-0.4 \\
<0.4\end{array}$ & $\begin{array}{r}29.9 \\
25 \cdot 0 \\
32.0 \\
7.8 \\
3.3 \\
0.0 \\
0.5 \\
0.7 \\
0.8\end{array}$ & $\begin{array}{r}21 \cdot 0 \\
27 \cdot 1 \\
33 \cdot 6 \\
3 \cdot 2 \\
8 \cdot 3 \\
1 \cdot 1 \\
2 \cdot 9 \\
1 \cdot 5 \\
2 \cdot 0\end{array}$ & \begin{tabular}{r|}
$33 \cdot 1$ \\
$30 \cdot 2$ \\
$19 \cdot 1$ \\
$9 \cdot 0$ \\
$2 \cdot 1$ \\
$5 \cdot 1$ \\
0.6 \\
0.7 \\
0.2
\end{tabular} \\
\hline \multicolumn{2}{|c|}{ Total allergen $\left(\mu \mathrm{g} / \mathrm{m}^{3}\right)$} & $19 \cdot 8$ & 4.5 & $16 \cdot 2$ \\
\hline
\end{tabular}




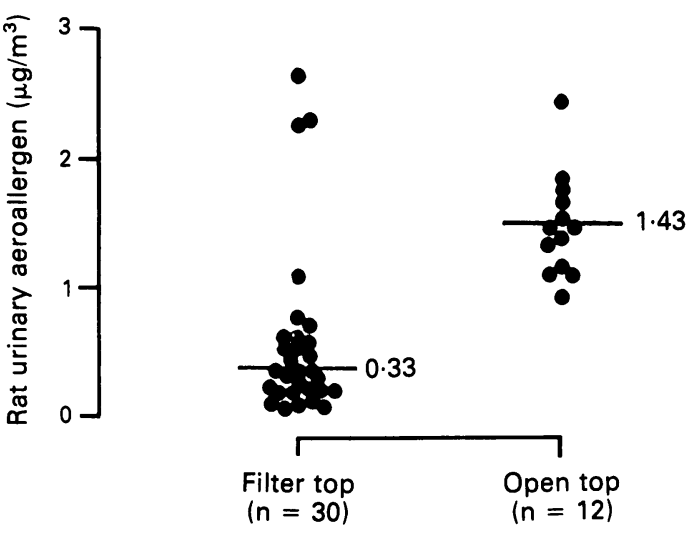

Figure 3 Comparison of cage design. Rat urinary aeroallergen concentrations measured when 30 rats were housed on woodchip bedding in filter top and open top cages, excluding those measurements made on cleaning out days for the open top cages. The geometric mean (GM) is indicated.

1.84 , and $0.85 \mu \mathrm{g} / \mathrm{m}^{3}$ respectively. Rat urine aeroallergen could still be detected when the room had been left unoccupied for one week (GM 0.12 $\left.\mu \mathrm{g} / \mathrm{m}^{3}\right)$.

\section{Effect of pump position}

Analysis of covariance showed no significant difference between the amounts measured by the four pumps.

\section{Effect of cleaning out}

The model was fitted without the pumps as a factor and the relation between the $\log _{e}$ allergen concentration and number of rats was found to be linear for both cleaning out and non-cleaning out days. There was no significant difference between the slopes of the lines (fig 4B). The allergen concentrations in the study room could be described by the following equation where $\mathrm{N}=$ number of rats and $\mathrm{D}=1$ on non-cleaning out days and 0 on cleaning out days:

$$
\begin{gathered}
\text { Allergen concentration }=\exp (-1.2158+ \\
0.0621 \times \mathrm{N}-0.4210 \times \mathrm{D})
\end{gathered}
$$

\section{PERSONAL AIR SAMPLING}

Table 2 shows the data collected during the routine care of the animals. The exposure associated with the removal of soiled wood based, in contact litter was nearly 10 times greater than that with soiled absorbent pads. Personal exposure decreased as the number of rats cleaned out decreased. When compared with the mean static RUA concentrations measured with the different litter types shown in fig 2 the personal exposure when cleaning out wood based litters was around 10-fold greater and fourfold greater for absorbent pads.

\section{Discussion}

Edwards et al ${ }^{15}$ showed that it was possible to influence the amount of animal allergens becoming airborne by increasing ventilation rate and relative
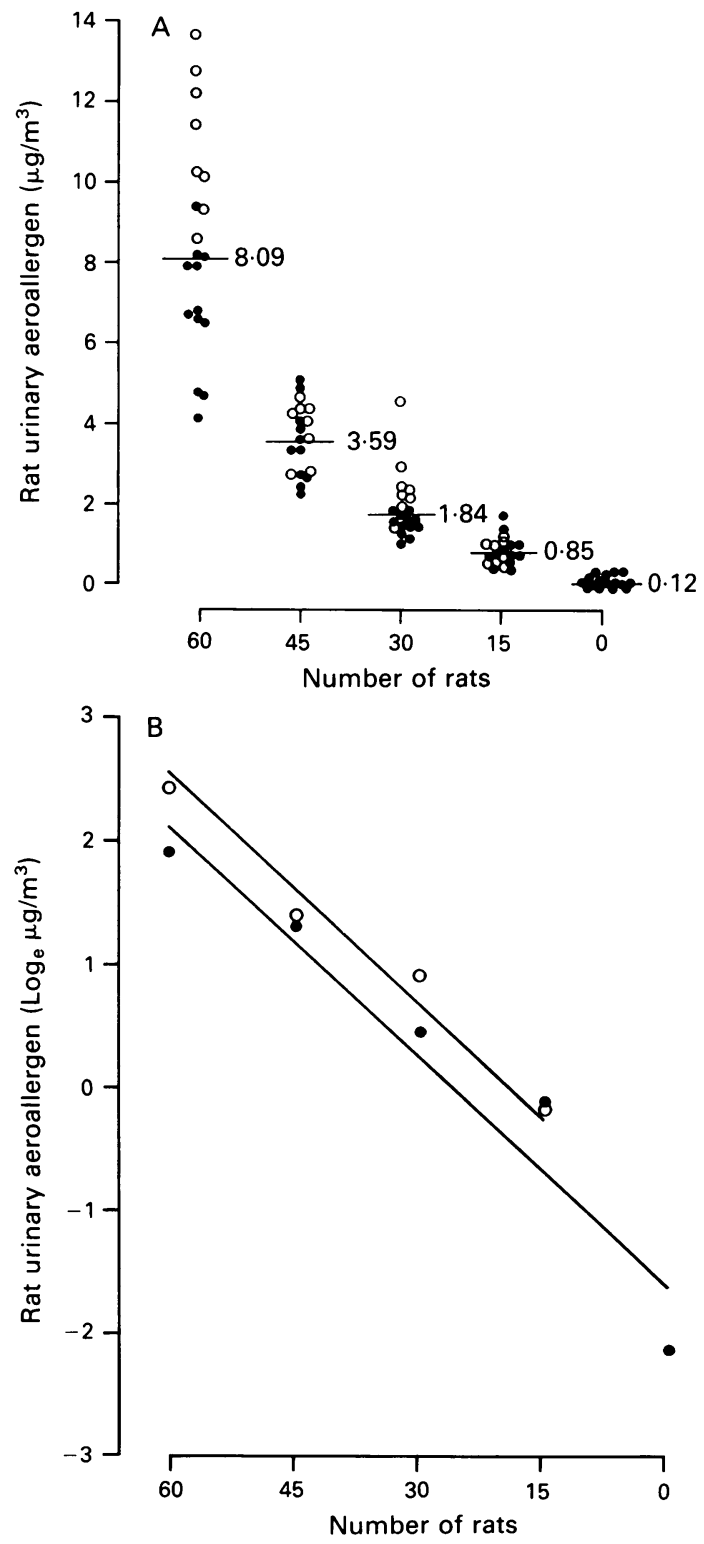

Figure 4 Effect of reducing stock density. A: Rat urinary aeroallergen concentrations measured when the stock density was reduced from $3 \cdot 1$ to no rats $/ \mathrm{m}^{3}$ ( 60 to no rats). The measurements made on cleaning out days are shown as open circles. The geometric mean (GM) is indicated. B: Relation between log, allergen and number of rats on cleaning out (open circles) and non-cleaning out (closed circles) days. Allergen concentration $=\exp (-1 \cdot 2158+0.0621 \times N$ $-0.4210 \times D)$, where $N=$ number of rats and $D=1$ on non-cleaning out days and 0 on cleaning out days. 
Table 2 Summary of personal air sampling results. Samples were collected during the cleaning out of varying numbers of rats housed on different litter types

\begin{tabular}{llll}
\hline Litter type & No rats & $\begin{array}{l}\text { No air } \\
\text { samples }\end{array}$ & $\begin{array}{l}\text { Rat urinary } \\
\text { aeroallergen } \\
G^{\star}\end{array}$ \\
\hline Absorbent pads & 60 & 2 & $\left.8 \cdot m^{3}\right)$ \\
Woodchip & 60 & 2 & $77 \cdot 4$ \\
Sawdust & 60 & 3 & $77 \cdot 9$ \\
Woodchip & 60 & 2 & $71 \cdot 6$ \\
Woodchip & 45 & 2 & $59 \cdot 2$ \\
Woodchip & 30 & 2 & $43 \cdot 1$ \\
\hline
\end{tabular}

${ }^{\star} \mathrm{GM}=$ geometric mean.

humidity, although significant reductions were achieved only under conditions that were uncomfortable to work in and detrimental to the health of the animals. We have found that it is possible to reduce significantly the concentration of rat urinary protein in air by simple and practical changes to husbandry procedures.

Highly significant reductions in rat allergen concentrations were achieved by replacing wood based in contact litter with non-contact absorbent pads, highlighting the important part that litter plays as a vehicle for allergen dissemination especially when in direct contact with the animals.

No major differences were found in the allergenic particle sizes generated on cleaning out days by the three litter types. Greater than $80 \%$ of the allergen was carried on particles larger than $8 \mu \mathrm{m}$, in agreement with observations from other studies. ${ }^{12} 22$

The use of filter top cages reduced RUA concentrations to values similar to those when the room was unoccupied by rats. It is possible that some leakage of allergen through the filter occurred before the litter was changed as two of the four measurements that were more than $1 \mu \mathrm{g} / \mathrm{m}^{3}$ were recorded immediately after a weekend. The values of the filter top cages on cleaning out days were not removed from the analysis and the efficiency of the filter top cages might therefore be underestimated due to allergen leakage at this time. A strong smell of ammonia was noticeable in the room after prolonged use and if filter top cages were to be used long term it would be recommended that the cages be additionally ventilated. Lincoln et $a l^{23}$ noted a further benefit of filter top cages in that they greatly reduce the risk of cross infection.

Like Swanson et al, ${ }^{22}$ we have shown that stock density influences rat allergen concentrations. Under the conditions of our study we found a linear relation between the $\log _{e}$ allergen concentration and rat numbers, and allergen concentrations generated during cleaning out and non-cleaning out days could be described mathematically. Stock density remains the simplest way of controlling allergen concentrations and emphasises the importance of keeping stock densities to a minimum.

Several groups have previously measured rat aeroallergen and have described concentrations that have varied by as much as three orders of magnitude, ranging from $\mathrm{ng} / \mathrm{m}^{3}$ to $\mu \mathrm{g} / \mathrm{m}^{3}$. $^{11-1322} 24$ Interpretation and direct comparisons of the results are difficult due to differences in husbandry conditions, elution techniques, and assay procedures. We have recently shown that aeroallergen yield can be increased 100fold by including $0.5 \% \mathrm{v} / \mathrm{v}$ Tween 20 in the elution buffer. ${ }^{19}$ Our results are similar to those of Edwards et $a l^{15}$ who also used Tween 20 in the filter elution buffer and RAST inhibition to measure the allergen content. A common finding between all groups is that personal exposure when working directly with animals can be three to 10 times that of the static or background concentration of the room. ${ }^{11-13}$

Our results show that rat urine aeroallergen concentrations can be significantly reduced by reducing the stock density of rat housing areas and by the use of filter top cages or, where these cannot be employed, by replacing contact litter with non-contact absorbent litter. Reduction of airborne rat urine protein concentrations in animal houses will almost certainly be associated with a decrease in incidence of disease as Reed et al found with humidifier contaminants. ${ }^{25}$ Extensive prospective studies are now required to define further the relation between occupational exposure to animal proteins and the incidence of disease. Effective sampling can clearly be achieved at low flow rates and can provide a powerful technique with which the hazards of exposure to animal allergens can be assessed and minimised.

We thank Mr Mark Divitini for computing assistance and the animal technician, without whose help and cooperation this project would not have been possible.

Requests for reprints to: Mrs S Gordon, Department of Occupational and Environmental Medicine, Emmanuel Kaye Building, National Heart and Lung Institute, Manresa Road, London, SW3 6LR.

1 Home Office. Statistics of experiments on living animals, Great Britain 1986. London: HMSO, 1986. (CM 187. ISBN 010 $101872 \mathrm{X}$.)

2 Gross NJ. Allergy to laboratory animals: epidemiologic, clinical and physiologic aspects, and a trial of cromolyn in its management. J Allergy Clin Immunol 1980;66:158-65.

3 Davies GE, McArdle LA. Allergy to laboratory animals: a survey by questionnaire. Int Archs Allergy Appl Immunol 1981;64:302-7.

4 Cockcroft A, Edwards J, McCarthy P, Andersson N. Allergy in laboratory animal workers. Lancet $1981 ; \mathbf{i}: 827-30$.

5 Slovak AJM, Hill RN. Laboratory animal allergy: a clinical survey of an exposed population. Br J Ind Med 1981;38:38-41.

6 Beeson MF, Dewdney JM, Edwards RG, Lee D, Orr RG. Prevalence and diagnosis of laboratory animal allergy. Clin Allergy 1983;13:433-42.

7 Agrup G, Belin L, Sjostedt L, Skerfving S. Allergy to laboratory 
animals in laboratory technicians and animal keepers. $\mathrm{Br} J$ Ind Med 1986;43:192-8.

8 Venables KM, Tee RD, Hawkins ER, Gordon DJ, Wale CJ, Farrer NM, et al. Laboratory animal allergy in a pharmaceutical company. Br J Ind Med 1988;45:660-6.

9 Botham PA, Teasdale EL. Allergy to laboratory animals. Biologist 1987;34:162-3.

10 Agarwal MK, Yunginger JW, Swanson MC, Reed CE. An immunochemical method to measure atmospheric allergens. $J$ Allergy Clin Immunol 1981;68:194-200.

11 Davies GE, Thompson AV, Rackham M. Estimation of airborne rat-derived antigens by ELISA. $J$ Immunoassay 1983;4: 113-26.

12 Price JA, Longbottom JL. ELISA method for measurement of airborne levels of major laboratory animal allergens. Clin Allergy 1988;18:95-107.

13 Eggleston PA, Newill CA, Ansari AA, Pustelnik A, Lou S-R, Evans III R, et al. Task-related variation in airborne concentrations of laboratory animal allergens: Studies with Rat $n 1$. J Allergy Clin Immunol 1989;84:347-52.

14 Blanchet $Y$. Evaluation of exposure to mouse and rat urinary proteins amongst employees of the Montreal General Hospital Research Institute. McGill University, 1988. (MSc Thesis School of Occupational Health.)

15 Edwards RG, Beeson MF, Dewdney JM. Laboratory animal allergy: the measurement of airborne urinary allergens and the effects of different environmental conditions. Lab Anim 1983;17:235-9.

16 Lewis DM, Bledsoe TA, Dement JM. Laboratory animal allergies. Use of the radioallergosorbent test inhibition assay to monitor airborne allergen levels. Scand $J$ Work Environ Health 1988;14(suppl 1):74-6.
17 Newman Taylor AJ, Longbottom JL, Pepys J. Respiratory allergy to urine proteins of rats and mice. Lancet 1977;ii: 847-9.

18 Home Office. Code of practice for the housing and care of animals used in scientific procedures. London: HMSO, 1989. (House of commons papers 107. ISBN 0102107890 .)

19 Atkinson S, Tee RD, Newman Taylor AJ. Optimisation of filter elution methods for aeroallergen monitoring. Allergologie 1989 (Abstr: B 1366E 22:03-04.)

20 Ceska M, Eriksson R, Varga JM. Radioimmunoabsorbent assay of allergens. J Allergy Clin Immunol 1972;49:1-9.

21 Tee RD, Gordon DJ, Lacey J, Nunn AJ, Brown M, Newman Taylor AJ. Occupational allergy to the common house fly (Musca domestica): Use of the immunologic response to identify atmospheric allergen. J Allergy Clin Immunol 1985; 76:826-31.

22 Swanson MC, Campbell AR, O'Hollaren MT, Reed CE. Role of ventilation, air filtration, and allergen production rate in determining concentrations of rat allergens in the air of animal quarters. Am Rev Respir Dis 1990;141:1578-81.

23 Lincoln TA, Bolton NE, Garrett MD. Occupational allergy to animal dander and sera. J Occup Med 1974;16:465-9.

24 Platts-Mills TAE, Heymann PW, Longbottom JL, Wilkins SR. Airborne allergens associated with asthma: allergens measured with a cascade impactor. J Allergy Clin Immunol 1986;77: 850-7.

25 Reed CE, Swanson MC, Lopez M, Ford AM, Major J, Witmer WB, et al. Measurement of IgG antibody and airborne antigen to control an industrial outbreak of hypersensitivity pneumonitis. J Occup Med 1983;25:207-10.

Accepted 16 September 1991
The British Journal of Industrial Medicine welcomes correspondence relating to any of the material appearing in the journal. Results from preliminary or small scale studies may also be published in the correspondence column if this seems appropriate. Letters should be not more than 500 words in length and contain a minimum of references. Table and figures should be kept to an absolute minimum. Letters are accepted on the understanding that they may be subject to editorial revision and shortening.

The journal now also publishes editorials which are normally specially commissioned. The Editor welcomes suggestions regarding suitable topics; those wishing to submit an editorial, however, should do so only after discussion with the Editor. 